\title{
The Campus-Wide Presentation: An Experiential Approach To Increasing Student Learning, Growth And Marketability
}

\author{
Natalie Ryder Redcross, Ph.D., Iona College, USA
}

\begin{abstract}
The purpose of this article is to describe and encourage an approach to a public relations course that can be applied to any discipline. Grounded in the experiential learning theory, students prepare for 16 weeks to present an issue-based campaign to a targeted, live audience at an oncampus venue. Using the course textbook and required readings as a guide, students are taught to "do" as the readings instruct, rather than be bound to merely memorizing the material. During the semester, the goal of the student evolves from earning a good grade, to attracting and enlightening an audience though public relations. While the project was assigned to public relations students, renditions of the described approach can be creatively applied to other disciplines interested in students acquiring real world experience outside of internships, within the safety net of their own campus.
\end{abstract}

Keywords: Campus-Wide Presentation; Experiential Learning; Increasing Student Learning; Student Growth; Student Marketability; Public Relations Campaigns

\section{INTRODUCTION}

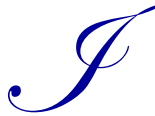

$\mathrm{n}$ the educational literature, learning occurring outside of the classroom frequently meets the definition of experiential learning (Caulfield \& Woods, 2013, p. 31). The Public Relations Society of America (PRSA, 2011/2012) accepts the following definition of public relations:

"Public relations is a strategic communication process that builds mutually beneficial relationships between organizations and their publics."

As the public relations definition emphasizes mutually beneficial relationships, experiential learning is a practical, constructive and valuable technique to integrate into a public relations curriculum that can be put into practice by actively practicing public relations, in addition to studying it.

Many a public relations textbook purports that the field of public relations requires characteristics such as curiosity, assertiveness, resourcefulness, worldliness, analytical abilities and creativity. While even the highest achievers in a class may understand and be able to apply the above definition and character traits to exam questions, the best prepared students will be those who experience it. Requiring a high level, team-oriented, researched-based live campaign event to be fully coordinated and presented by students is similar to internship experience expected from most hiring public relations organizations. Skills acquired are research design and implementation, team building, writing, media relations, event planning, presentation building, networking and public speaking. Character skills acquired include flexibility, teamwork and collaboration, multitasking, and above all, optimism and realism. 


\section{BACKGROUND}

For 12 weeks out of a 16-week semester, students in the capstone public relations course designed a public relations campaign around an issue or cause, and prepared to present it at an on-campus venue to a live audience of college faculty, staff, students and community members. The addition of the experiential component to students' learning experience adds value, purpose and practice.

Research shows there is demonstrated value in public relations' students practicing public relations while in college through a classroom experience as it benefits them to begin "working" in the classroom within a 16-week semester, rather than relying on outside internships for work experience. The study of public relations is not abstract; it is most effective when it takes place in the context of its real-world application. Only then can students learn to deal with the incongruities and dynamics of the marketplace or business world in ways that are appropriate, effective, ethical, and a good investment for the client (Gleason and Violette, 2012).

\section{THE EXPERIENTIAL LEARNING METHOD}

The Association for Experiential Education (2014) defines experiential education as: "Experiential education is a philosophy that informs many methodologies in which educators purposefully engage with learners in direct experience and focused reflection in order to increase knowledge, develop skills, clarify values, and develop people's capacity to contribute to their communities."

Caulfield and Woods (2012) described students as being exposed to world events that require considerable cross-cultural understanding and recognition that education is far more than learning facts about specific disciplines and diverse groups when sitting in a classroom. The authors further explained that college curricula are becoming more interdisciplinary in practice as evidenced by the interweaving of topics such as civic engagement, ethics, global studies, leadership and social responsibility within course work across curricula, with the intended goal of influencing students to become more socially responsible global citizens. Increasingly more learning is taking place within communities versus solely within classrooms. With this study drawing from this definition, increased knowledge, skill development, confidence and risk-taking behavior are the results of experiential learning and the focus of the method used by the professor.

According to a study focusing on today's millennial-generation undergraduates, these students do not want to be passive learners, but active participants in shaping their own learning experiences. The practical experiences they desire allow them to use their knowledge and make use of their skills through practice. The research suggests that educators be prepared to establish institutional and pedagogical practices that are responsive to their students' needs and interests. which can help students realize their full potential (Bowen et al., 2011).

Educators from Aristotle to John Dewey have acknowledged the close connection between experience and learning. Dewey (1938) expressed the belief that "all genuine education comes through experience" (p. 25). Putting Dewey's philosophy to work has been effective in public relations classrooms, and several studies (Dewey, 1938; Kolb, 2009; Sibthorp, Schumann, Gookin, Baynes, Paisley, \& Rathunde, 2011) have shown the effectiveness of learning through experience; but students have also appreciated the opportunity to test their skills in a real situation instilling confidence and building their resume.

Because students are involved in the decision-making process with the professor almost from beginning of the semester, they are not perceived as merely receivers awaiting instruction and guided solely by the syllabus. Instead, students are expected - even required - to be active participant and decision makers in their destiny for the semester (Green \& Ballard, 2010).

\section{PUBLICITY CAMPAIGNS PUBLIC RELATIONS CAPSTONE PROJECT AND LIVE EVENT}

Publicity Campaigns is an undergraduate course within mass communications that focuses on developing and implementing public relations campaigns, which includes hands-on experience in designing and producing materials for campaigns, and emphasis on use of planning and evaluation techniques. 
The course is typically made up of juniors and seniors and is an advanced-level course with introduction to public relations course as prerequisite and several other public relations courses taken prior. It is expected that these students are familiar with the fundamentals of public relations, have strong writing skills and hence, should be prepared to implement what they learned in their previous courses.

This paper highlights an experiential approach to teaching involving active use of text using the close reading method, which required a combination of study (reflection papers based on the reading), application (use of the public relations process to design, plan and build a public relations campaign) and action (presentation of the culminating project in the form of a campus-wide public relations campaign event).

The premise of each student campaign was to bring an issue or cause to life through the use of public relations research, planning, strategies, tactics, publicity and marketing. Students were required to design, plan and execute an hour-long campaign event targeted to a specific audience within their campus population.

For 16-weeks, 20 students in groups of five used their assigned textbook and readings as a frame of reference, research tool and guide. They were assigned a course of study that was sequentially and strategically coordinated to the process of designing and building their public relations campaign to be presented to each team's target audience at the college. A full written report version of the campaign was required as the final project.

Assessments included reflection papers that applied their public relations campaign topics to each public relations process phase, campaign event, public relations final report binder including research instruments and results; press releases; feature articles; evidence of communication between guests, vendors or other event participants; social media platform; photographs of event; evaluation instruments and results; personal reflection papers; and any other material connected to their publicity campaign. Among the most important assessment, however, is audience numbers: 40 plus is considered strong attendance for each team presentation.

\section{Project Guidelines}

Students are given clear guidelines during the first week of school and are given the task of formulating and outlining their campaign goals, teams, individual roles, objectives, target audience and event logistics.

Goal: The goal is to build and an informational or educational campaign raising awareness about a cause or issue, to be presented to an audience in a 1- to 2-hour campus-wide event. Students come up with a campaign idea based on deep group discussion, research and finally, professor approval. They select a campaign issue with the intent of educating fellow students, professors and/or administrators, or demographic groups within these audiences, such as female or male, athletes, students in particular majors, depending on the audience they target. The learning objectives are research, critical and strategic thinking and implementation.

Teams: Each team of five designs, coordinates and presents its own campaign. While much of the group work is accomplished during class with the guidance of the professor, students are expected to meet outside of class as well. According to Allison (2008), the use of self-directed student teams offers collaborative learning, while simulating the reality of life in a public relations agency.

In the case of this project, the simulation occurs as a real campaign presented to a real audience in efforts to be informative, enlightening, persuasive and influential. The learning objectives are collaboration, self-discipline, group dynamic development, and peer evaluation.

Individual Roles: Each group member takes on the lead of a specific role (e.g., primary writer, publicist, event planner, documentarian, presentation specialist) for their own growth and so the professor can assess individual work. This also ensures an equal distribution of tasks and assignments. Students make the decision based on strengths. The lead group member is expected to delegate tasks within the role, so everyone contributes to each category. The learning objectives are public relations tool development and accountability. 
Objectives: Each team must have a clear, measureable objective for its audience in response to the campaign issue (e.g., audience participation, responses, feedback). Additionally, by way of their public relations efforts, teams are expected to attract an audience of at least 40 guests. The learning objectives are strategic thinking, qualitative and/or quantitative research and evaluation.

Target Audience: Target audiences depend on the campaign issue. Teams seek audiences based on a particular interest, or female/male students, majors, or by classification. The learning objectives are identifying and understanding audiences and demographics.

The Publicity Campaign Event: Team members are required to attend their event, as well as participate in pre-event set up and post-event clean up. Giveaways, prizes, food, decorations and any other event materials can only be acquired through donation; students are not permitted to spend personal money. This teaches students about the level of resourcefulness expected from public relations specialists. Advertising is not permitted, so students must use the public relations skills they have studied. All communication is done using public relations and marketing strategies. The learning objectives are resourcefulness, marketing, and networking.

\section{Preliminary Work (Weeks 1-3)}

During the first week of the semester, the students were told about the project and what was expected, and were required immediately to begin forming groups of four or five and brainstorming issues and causes. Within the first 3 weeks, students must accomplish two goals: study and apply the fundamentals of the public relations campaign outlined in their textbook by writing a series of reflection papers connected with each stage of the public relations campaign planning (e.g., the first two reflection papers were on the meaning of public relations in relation to campaign building, and the importance of research). This way, they were compelled to read the book and directly connect the text content to building their campaign.

\section{Selecting the Campaign (Weeks 3 and 4)}

“. . . excellent strategic planning relies on strategic research” (Diggs-Brown, 2012, p. 109)

The class subscribed to this quote when considering their audience, followed by conducting the appropriate research and learning that no campaign is successful without a solid research plan. After writing a full reflection paper on research methodology, students began actual research on their cause of choice. This stage is crucial, and one in which the importance of research is truly realized because it is during this stage that students reject causes they believe are insignificant or irrelevant. Historically, this is the students' least desirable phase of the campaign process. The sighs and bored expressions are typical displays of their feelings toward research. It is the nonverbal translation for "this is tedious; let's hurry and get to the fun stuff." As it is often difficult for students to appreciate the rigor required in research, it is after they have conducted their focus groups, tallied their questionnaire responses, and reviewed their interview discussions that they understand the dangers of making presumptions and drawing conclusions about their counterparts and peers. Entire campaign ideas have been modified or changed after this stage - a major learning lesson for the students. In this crucial stage, the audience-centered approach is realized. After experiencing disheartening moments that all researchers have had-inconclusive findings, learning that a hypothesis is not what was predicted or hoped it would be, and other indicators that the original course of study will not work, and the work must begin again, the students fully understood the value of research and were grateful that they were not stuck mid semester realizing their chosen campaign idea would be a flop.

Students conducted formative research, including questionnaires, focus groups and personal interviews, and iterative research, in which they presented their event idea and rough presentation to their classmates (pretest).

Strategies of planning, communication, event planning details and evaluation followed, but not through quizzes, exams or research reports. Instead, teams went through the rigorous process of fact finding - designing instruments to conduct primary research and obtaining permission to distribute and conduct surveys, focus groups and interviews. 


\section{Planning the Campaign (Weeks 5-8)}

Once the preliminary research is completed, the planning, discovery and analysis stage begins, which consists of creating the building blocks for the event, such as logistics, visuals, presentation and all that is included for the planning of the event. Students spend the next 2 weeks analyzing the research in which the point of focus is problem and opportunity identification, and how the problem or opportunity affects the team and its audience.

At this point, students become less consumed with the proverbial "good grade." As the project nears, they all want their events to be well received and experience the healthy fear, anticipation, pressure and incentive to impress their peers and audience, and not just their professor.

During these weeks, the classroom is bustling. The professor is meeting with individual groups for approximately 10-15 minutes during each class, while the other groups are working on their own or gathering data, interviewing, visiting food vendors, phoning and emailing potential guest speakers and meeting with anyone involved in making their event happen. For this type of project to work, allowing the groups to coordinate event business during class time is imperative, as work schedules make it impossible for some students to accomplish all group tasks outside of class.

This works well for the professor and for assessment of the teams, as their work is tracked and documented. Teams keep a $\log$ of all they do and the data must be documented in the final report.

\section{Getting the Word Out Around Campus: Communication and Implementation (Weeks 6-10)}

While planning, communication and implementation overlap, they are being carefully plotted and executed mid-semester. Students are putting on an actual event and a real audience is expected to attend. They must attract their audience through strategic public relations, such as a published article in the student newspaper and/or other campus publications, aired announcements on the college radio and television stations, and social media and marketing tactics. Classroom, sorority, fraternity, club, and residence hall presentations (students refer to them as "dorm storms") and talks are expected, in which students take five to ten minutes to pitch their event to those groups. No paid advertising is permitted; students are assessed in large part by the public relations results they have achieved by the end of their campaign.

\section{The Dress Rehearsal: Monitoring or Iterative Research (Week 8)}

Prior to the campaign launch, pretesting is done in the form of peer evaluation. Each team performs somewhat of a dress rehearsal presented to their classmates that mirrors the real event as much as possible. This is valuable research and planning opportunity for the groups - an exercise in evaluation and critique. At this time, classmates offer constructive criticism, suggestions and new ideas, and the students in the presenting group is required to ask their classmates clarifying questions: Is our Power Point clear? Are we talking too much? Were you bored? Should we serve food before or after our video clip? The class is encouraged to candidly suggest any change or revision in their classmates' campaign. The classroom breeds a culture of support, not competition.

Students appreciate this form of pretesting more than any other research they conduct. They learn from their classmates, who essentially are them. With a clear understanding of significance of this exercise, major changes in campaign presentations are made after this day.

\section{The "Big Day" Approaches (Weeks 9-12)}

With the classroom presentations complete, the public relations campaign is now 2-3 weeks away. During this phase students focus on adhering to ethical practices and professional standards as they are faced with real and sometimes intimidating and discouraging situations connected to their event. In one case, a student team thought an administrative office on campus was holding an event similar to theirs on the same date and time. Students in the group were very disturbed by this, as they said the office knew about their event weeks prior, and many of the same resources and ideas were used. They were asked, "What is the most ethical way to handle this situation? How can 
you ensure your behavior is professional, even if you don't believe the behaviors of those above you are?" Luckily in the end, the students were mistaken, and the administrative event was held on a different day.

Although tempting at times due to time and pressure, students had to be careful to avoid violating school policy. One disconcerting scenario occurred when one of the student groups received a curt letter from campus food services informing them that they were made aware of donations of food they received from off-campus vendors. The letter reminded the students that the campus organization has right of first refusal, and that the students should have considered them first. It turned out that food services was mistaken; they were asked first, and in return asked for payment, which goes against the class policy; hence, the students had to refuse. Still, it made for an uncomfortable situation for the students, but a good dose of real experience.

Throughout the planning process, detailed drafts of the public relations plan or report are due, and returned with feedback. In addition, teams were required to submit evidence of their publicity campaign around campus including publications, flyers, social media, classroom, residence halls and meeting announcements and other media alerts.

\section{The "Big Day" Arrives (Weeks 12-14)}

On each group's "big day," each team puts on an hour-long public relations campaign during campus activity hour, which is a campus-wide allotted hour (noon to 1p.m.) is class-free, to allow time for and to encourage students to engage in campus clubs, associations and events. On the designated event day, all students from the course are required to attend each teams' event, but they do not count as the presenting group's target audience. Students are allotted 1 hour for preparation time at their venue before start time, during which nervous students are decorating, setting up food and display items, checking their technology and rehearsing their speeches. This occurs while they are anxiously peeping through the venue doorway hoping for passersby to become audience members and to fill their seats. They count down the minutes to start time. The professor is present all the while taking notes, and trying not to interfere and allow the groups to own their shortcomings and successes. It is truly a sight to see!

When the 12 pm hour strikes, they are on—ready or not. The audience—large, medium or small—awaits them.

Some students have shared that on this day and days and hours before the event they have had a type of anxiety never before experienced; loss of sleep and appetite, nausea and crying fits are not uncommon. They do, however, survive, and feel especially proud of themselves for putting on such a production. It is especially rewarding to receive feedback from audience members beyond their professor, friends and classmates.

\section{The Aftermath (Weeks 13-16)}

At the close of each event at around $1 \mathrm{pm}$, students take their bow, receive their praise, collect their evaluation data from the audience and clean up the venue. Elation and relief are understatements in terms of what they are feeling; at this point, student teams have completed all the front-end work and can finally breathe easily.

After a week or so of rejoicing, recollecting and reflecting, students are reminded that their work is not over, as their event must be measured as to whether or not their goals and objectives were met. All of their hard work must be documented in a written public relations campaign report, usually in the form of a thick binder. The binder includes all the work that has been attempted, tallied, published and completed, all in a meticulously organized and highly detailed public relations campaign report. The evaluations must be tallied and reported, and included in a deeper reflection paper as a part of the final report.

\section{Evaluation}

Past student publicity campaigns have included Food and Fitness (on campus healthy options and easy exercise); Volunteerism; Color our World with Diversity; Kicking Butt the Female Way: Self Defense for Women; All You Need to Know About Internships, For Students, By Students; and Stress Free 2013 (and how we as students can decrease it). In the past 2 years, these projects have been evaluated by class attendance and active participation 
and evidence of publicity throughout the semester. The final public relations binder, submitted by each group, included an individual in-depth student reflection seen and read only by the professor describing the students' experiences - the positives and negatives. In the near future, a pre- and post-project questionnaire will be given to capstone students to evaluate and assess campaign goal expectations, performance, and results as well as team, project and self-evaluation more deeply and specifically.

\section{DISCUSSION}

Overall, this project is successful on numerous levels; however, challenges and limitations should be considered when designing such a course. In fact, it is the recognition of the limitations that allows for more success for future adjustment and preparation for glitches. Challenges should be documented and remembered so that they will be repeated if avoidable, and so they can be used as valuable teachable lessons for both student and professor. The challenges include:

1. Helping students understand that they must have a clear goal for their event before they can start planning it: They cannot wait to begin planning the activities that will occur at the event, but they often do not know fully what they want the event to accomplish.

2. Acclimating them to the unusual class setting, which is particularly informal, requiring independence and self-discipline: There is an expectation of due diligence and honesty, without the need for constant reminders and daily direction. Students often have difficulty adjusting to the lack of structure they are accustomed to in a typical classroom setting with lecture format.

3. Facilitating understanding true accountability: It is daunting for them to be responsible for more than their personal assignments, as group members heavily rely on each other to produce results. Groups are creating a real event for which they are fully responsible, and they are establishing relationships with different people to ensure success, such as the Student Development office, campus venue coordinators, room reservationists, security, technology offices, and food and merchandise vendors.

4. Preparing students for a different type of assessment: Not having to study for a traditional exam is a joyful thought at first, but students struggle with understanding out how they will be assessed; criteria such as attendance, consistent contribution, proactivity, teamwork and initiative can seem vague and confusing. While the text-based assessments are concrete, graded assignments, the non-graded intangibles assignments are equally important. For example, if a group agrees to meet once a week outside of class to prepare for its campaign, and one group member misses several meetings without a valid excuse, once the professor is alerted, this goes against the group member's final grade for participation.

5. Encouraging the use of time management strategies: This course is a major wake-up call for procrastinators. The fact that their final project is based on 16 weeks of documented work and public relations and marketing tools they should have created is treated by some students as work that can wait until the very last moment. They later learn that no amount of "cramming" can help them, as they cannot create a public relations plan at the last minute. It will only be a complete report of they are keeping copious and clear notes on a weekly basis.

The pros of this assignment, however, certainly outweigh the cons, not only for the students as previously outlined, but for the audience members' benefit as well:

- The campus audience has the opportunity to be informed about a significant topic that directly concerns them.

- Interest level is higher when students are educated by students, which is not often the case at a college campus.

- $\quad$ Students presenting are encouraged and motivated by feedback from their peers.

- Student audience members share their thoughts and feedback on social media platforms, making their students public relations campaigns stronger.

- $\quad$ Projects and performance are usually superior; fear of being embarrassed in front of peers is a huge motivator. 


\section{DEMONSTRATED EVIDENCE OF STUDENT LEARNING}

After having taught the capstone course for four semesters, the challenge of managing the teams and putting in numerous extra hours remains a constant. However, what also remains a constant is the satisfaction and fulfillment gained from witnessing the majority of the students learn and take away more through this activity than they might have through a lecture-based course or through mock activities and scenarios. Learning objectives achieved are as follow:

\section{Active, Experiential Learning Models: A Wealth of Research}

Given the wealth of research, few would argue against the shift from the professor acting as "sage on the stage" to the more interactive "guide on the side," or the educational movement touting a student-centered model rather than the lecture-based teacher-centered model (Morrison, 2014). Research also supports the active and experiential styles of learning extolled in the research for teaching public relations courses and many other disciplines (provide citations here). In addition to my own success rate in teaching this class in the past, communication and education research overwhelmingly supports this line of teaching and offers numerous examples of evidence of improved student learning and better preparation for the work force (Coombs \& Rybacki, 1999).

\section{Motivational Value of the Student-Centered Approach}

I have used a variety of teaching approaches throughout my years in the college classroom. In the beginning stages, like most, I used the traditional lecture method, weaving in interactive and experiential activities. It was always those activities that the students valued most and, based on student evaluations and personal discussion, it was the content in those activities that students retained. Students remembered the activity because they did it: organized it, designed it, discussed it and presented it. They were actively engaged and involved throughout the process. Because they are being observed and judged by their peers on campus, students taking this course are highly motivated to successfully engage, inform, educate, entertain, and impress their peers. This self-motivation and skill set are both healthy and necessary for students because the grading system ends after college and they will have to use these persuasive tactics in the workplace.

\section{Preparation for the Job Market in Public Relations: Professional Experience}

Leaders in public relations have been candid about what they are looking for in potential employees, as well as how prepared or ill prepared graduates are. I design the course largely based on the comments of public relations professionals about today's entry-level employees. My intent is to expose students to an opportunity to acquire the skills the professionals seek. An article from Public Relations Tactics, "What PR Leaders Look for in Job Candidates" (2009), highlighted executives at Verizon, ITT, US Airlines, IBM, Lenovo, Elan Pharmaceuticals, MillerCoors and Baxter International, who discussed the most highly prized characteristics and skills for public relations employees. I designed the live event assignment and its components in large part to help students acquire those skills and to prepare students for what leaders in the field want.

Among the skills desired were strength in the basics — strong and persuasive writing and verbal skills; the ability to express oneself and help others do the same in a clear, cogent way; energy and creativity; ability to break through the clutter of messages; strong work ethic and sense of urgency; leadership skills; ability to work independently; and a customer-centric attitude.

All of the above are components of the outlined course exercise. The capstone project included leading and managing a team, self-motivation and self-discipline and the absence of exams or tests in memorization. Students' success in the course was based on their publics and teammates' attitudes and responses to their campaign efforts. Writing skills strong enough to attract audiences and be published was expected. Creative and critical thinking for the selection, design and implementation of a campaign that mattered to their public, and variety of public relations writing styles were taught and applied. Mastering these skills in public relations creates marketability, which is the purpose for being in college. Resume building experience (outside of internships) such as designing a professional event and attracting real audiences through the written word and other public relations strategies and tactics are a 
real draw to potential employers. Providing students with a semester-long snippet of real world experience is a much-needed (and appreciated) resume builder. Students have reported that largely because of this activity, potential employers called for an interview, and inquired about in the details of this course in their interview discussion.

\section{Student Reflections}

It is the students' reflective views that truly speak to evidence-based learning. In their self- and course assessment, understanding of the experience, level of fulfillment and how much or little they value the course is telling of what worked and what did not.

At the end of the semester when all parts of the project are completed, students are asked to share in deep reflection about their experience - all aspects of it. This is the only component of the campaign that is not shared with team members and is only read by the professor, ensuring students' comfort in expressing their opinions about the experience, even information about their teammates. Comments about students' public relations campaigns have shed light on why this project, semester after semester, increases their knowledge of public relations and improves their level of professionalism.

In the following excerpts from their reflection papers, organized by themes, students addressed several aspects of the course activity that illustrate valuable and increased learning:

\section{Working independently and with teams}

"When we first got into our group and started this project it was a little confusing and overwhelming. I honestly did not think that five college students would be able to put together such a professional event, but as the semester went on everything fell into place perfectly."

"We stuck to our roles and also reached out to help people in other roles. If we wanted this event to be a success we needed to put in a ton of work as a team and teamwork was one of our biggest strengths."

"None of us knew each other very well before this project and I am glad for the opportunity to collaborate as a team with new people, as we likely often have to do in the professional world."

\section{Public relations skills, learning, growth and job marketability}

"I feel as though we learned a lot about how to effectively use research to plan and publicize an event based on our target audience."

"I was very excited to find out that our event was covered by the Iona newspaper on their website and that my correspondence with a staff writer helped lead to that."

“... as a senior at Iona College, I feel as though I established a high platform of myself, for the current student body and as well as for the future student body."

\section{Memorable takeaways:}

"I think that with a bit more practice, we could have had a more interactive type discussion at the end of our presentation, that might have spurred people into more involvement and action towards our cause after the presentation had ended."

"I think a PowerPoint presentation would have been beneficial for people to see the numbers themselves because it's more difficult to grasp information when you cannot physically see it for yourself. The lack of this visual definitely took away some of the impact and effectiveness of the information and purpose of our campaign." 
"I believe that our presentation went very well, but if I were to go back and change anything I would have added graphs or diagrams in order to give a more visual presentation of our statistics."

\section{Personal reflections}

"Feeling like you made a difference is a very rewarding emotion."

"I believe through our message, it encouraged more students and faculty to get involved and make changes within the Iona campus."

"The event was a great success. Afterwards, it was spoken about throughout social media sites, students amongst each other and faculty members. We felt that our message really did move the Iona community."

\section{CONCLUSION}

While it has been done, more professors in disciplines outside of public relations should consider a live, campus-wide event for their class. It gives students resume building experience, fosters public speaking and presentation skills, helps them utilize their strengths outside the parameters of the classroom and allows their peers to witness their strengths and the skills they have attained. This project translates to other disciplines in two ways: first, any professor can use an activity in a course textbook or required reading for more than a source of study and exam preparation. A single chapter or more can be turned into a real situation, and in turn allow for an appreciation of the usefulness and necessity of the textbook. Second, with creative thought the live event can be used in many disciplines, with a campus audience to witness the work. As long as students are able to bring a case study, activity or project to life in some way, with witnesses other than their professor and classmates, a different sense of responsibility and commitment is achieved.

Despite the rich educational heritage of the concept, and while individual professors have long been on board, universities as a whole have been slow to incorporate extensive experiential learning methods for undergraduates and reticent to take advantage of the "rich resource" of practicing experts outside academia (Green and Ballard, 2010-2011).

I hope that my success with an assignment of this nature will encourage further study of experiential learning in college curricula and community organizations. As indicated by past research that supports and complements my experience teaching this course, experiential, active learning exposes students to authentic social experiences that are more likely to engage them in future socially responsible behaviors, transforming them into agents of positive social change within their communities, and this is one example of an experiential approach that can cross disciplines and engage students in strategic, hands-,on, higher-order thinking that will prepare them for the workplace.

\section{AUTHOR INFORMATION}

Natalie Ryder Redcross is currently an Assistant Professor in the Department of Mass Communication at Iona College. Her research focuses on incorporating experiential education and nonprofit organizations in the classroom, as well as the Black experience in mass communications. Redcross is an Iona College graduate with a BA in Communication Arts and MS in Journalism. She received her Ph.D. from Howard University in Communication and Culture. Redcross' career in public relations spans from nonprofit organizations, to arts and entertainment to K-12 education

\section{REFERENCES}

Allison, W. A. (2008). A best practices service learning framework for the public relations campaigns course. Journal of the Scholarship of Teaching and Learning, 8(2).

Anonymous. (2009). What PR leaders look for in job candidates. Public Relations Tactics, SO01, doi: 6C-120904.

Association for Experiential Education. (2014). What is experiential education? Retrieved from http://www.aee.org/about/whatIsEE/.html 
Benander, R. (2009). Experiential learning in the scholarship of teaching and learning. Journal of the Scholarship of Teaching and Learning, 9(2), 36-41.

Ballard, G. H., \& Green G. (2010) No substitute for experience: Transforming teacher preparation with experiential and adult learning practices. SRATE Journal, 20(1), 12-19.

Bowen, G., Burton, C., Cooper, C., Cruz, L., McFadden, A., Reich, C., \& Wargo, M. (2011). Listening to the voices of today's undergraduates: Implications for teaching and learning. Journal of the Scholarship of Teaching and Learning, 11( 3), 21-33.

Caulfield, J., \& Woods, T. (2013). Experiential learning: Exploring its long-term impact on socially responsible behavior. Journal of the Scholarship of Teaching and Learning, 13(2), 31-48.

Chia, J. (2009). Intercultural interpretations: making public relations education culturally relevant. Journal of University Teaching \& Learning Practice, 6(1), 39-48.

Coombs, T. W., \& Rybacki, K. (1999). Public relations education: Where is pedagogy? Public Relations Review. 25(1), 55-63.

Cunningham, I. (2007). Do we really want all learning to be experiential? The hot stove effect. Development and Learning in Organizations, 21(3), 4-5.

Darling-Hammond, L., \& Baratz-Snowden, J. (Eds.). (2005). A good teacher in every classroom: Preparing the highly qualified teachers our children deserve. National Academy of Education Committee on Teacher Education. San Francisco, CA: Jossey-Bass.

Dewey, J. (1938). Experience and education. New York, NY: Macmillan.

Diggs-Brown, B. (2012). Strategic public relations: An audience-focused approach. Boston, MA: Wadsworth.

Eyler, J., \& Giles, D. E. (1999). Where's the learning in service-learning? San Francisco, CA: Jossey-Bass.

Garner, I. (2000). Problems and inconsistencies with Kolb's learning styles. Educational Psychology, 20(3), 341348.

Gleason, J. P \& Violette, J. L. (2012). Integrating service learning into public relations coursework: Applications, implications, challenges, and rewards. International Journal of Teaching and Learning in Higher Education, 24(2), 280-285.

Green, A. J. (1995). Experiential learning and teaching-A critical evaluation of an enquiry which used phenomenological method. Nurse Education Today, 15(6), 420-426

Public Relations Association of America. (2011/2012). What is public relations? PRSA's widely accepted definition. Retrieved from http://www.prsa.org/aboutprsa/publicrelationsdefined/\#.VEAaL9q9KSM.html

Kendall, R., \& Anderson, J. W. (1986, May). The research base for a public relations curriculum: A national survey of topics "essential" to a public relations curriculum. Paper presented at the Annual Meeting of the International Communication Association, Chicago, Ill.,

Kolb, A. Y., \& Kolb, D. A. (2009). The learning way: Meta-cognitive aspects of experiential learning. Simulation \& Gaming, 40(3), 297-327.

Kreps, G. L., Frey, L. R., \& O'Hair, D. (1991). Applied communication research: Scholarship that can make a difference. Journal of Applied Communication Research, 19(1-2), 71-87.

Mantle-Bromley, C., Gould, M., McWhorter, B. A., \& Whaley, D. C. (2000). The effect of program structure on new teachers' employment and program satisfaction patterns. Action in Teacher Education, 22(1), 1-14.

Montrose, L. (2008) International study and experiential learning: The academic context. Frontiers: The Interdisciplinary Journal of Study Abroad, Retrieved from: http://www.frontiersjournal.com/issues/vol8/vol8-08_montrose.html

Morrison, C., D. (2014). From "sage on the stage" to "guide on the side": A good start. International Journal for the Scholarship of Teaching and Learning, 8(1), 1-15.

Pedrosa, H., T., Almeida, P. A., Teixeira-Dias, J. J., \& Watts, M. (2006). Students' questions: Building a bridge between Kolb's learning styles and approaches to learning. Education \& Training, 48(2), 97-111

Sibthorp, J., Schumann, S., Gookin, J., Baynes, S., Paisley, K., \& Rathunde, K. (2011). Experiential education and lifelong learning: Examining optical engagement in college students. Journal of Experiential Education, 33(4), 388-392.

Simons, L., Fehr, L., Blank, N., \& Connell, H. (2012). Lessons learned from experiential learning: What do students learn from a practicum/internship? International Journal of Teaching and Learning in Higher Education, 24(3), 325-334.

Taggart, A., \& Crisp, G. (2011). Service learning at community colleges: Synthesis, critique, and recommendations for future research. Journal of College Reading and Learning, 42(1), 24-44 


\section{NOTES}

